\title{
Malposition of the coronary ostium
}

INSERM

\section{Source}

INSERM. (1999). Orphanet: an online rare disease and orphan drug data base.

Malposition of the coronary ostium. ORPHA:99090

Malposition of the coronary ostium is a rare coronary artery congenital malformation characterized by displacement of one of the coronary arteries, originating closer to the aortic root or to the commissural area. The anomaly is considered to be asymptomatic, however, it may impose surgical difficulties during aortic root surgery. 